\title{
Educação ambiental na perspectiva da educação inclusiva
}

\section{Environmental education from the perspective of inclusive education}

\author{
Jorge Amaro de Souza Borges*
}

Resumo: O presente trabalho aborda a articulação da Política Nacional de Educação Ambiental com a Política Nacional de Educação Especial na Perspectiva da Educação Inclusiva, a partir de experiência do Laboratório de Educação Ambiental Inclusiva (LEAI), proposto pela Fundação de Articulação e Desenvolvimento de Políticas Públicas para Pessoas com Deficiência e Pessoas com Altas Habilidades no Rio Grande do Sul (FADERS), órgão responsável por coordenar e articular projetos e ações direcionadas a essa parcela da população. De acordo com os dados do Censo Demográfico de 2010 do Instituto Brasileiro de Geografia e Estatística (IBGE, 2010), aproximadamente 45 milhões de brasileiros declararam possuir alguma deficiência, o que significou um salto de 1,41\% em 1991 para 14,5\% da população em 2000, chegando a 23,9\% em 2010. Objetivamente, nossos trabalhos buscaram primeiro refletir sobre a necessidade de diálogo entre inclusão, acessibilidade, sustentabilidade e direitos humanos, e atuar na construção de mecanismos que possibilitassem ações práticas, tendo atendimento, capacitação e pesquisa como eixos centrais. A partir disso, procuraram analisar a relação acessibilidade - sustentabilidade no contexto da garantia de direitos humanos, como ferramentas de construção de políticas públicas inclusivas e também sustentáveis.

Palavras-chave: Inclusão social. Pessoas com deficiência. Acessibilidade. Cidadania. Sustentabilidade.

Abstract: This paper discusses the relationship between the 'National Environmental Education Policy' and the 'National Policy on Special Education from the Perspective of Inclusive Education', from the experience of the Laboratory of Inclusive Environmental (LEAI) proposed by the Foundation of Coordination and Development of Public Policies for people with Disabilities and People with Special Needs in Rio Grande do Sul (FADERS), a body responsible for coordinating and promoting projects and activities aimed at this segment of the population. According to Census data for 2010 from the Brazilian Institute of Geography and Statistics (IBGE, 2010), approximately 45 million Brazilians have declared a disability, which meant a jump from $1.41 \%$ in 1991 to $14.5 \%$ of the population in 2000 , reaching 23.9\% in 2010. Objectively, our studies firstly attempted to reflect on the need for dialogue between inclusion, accessibility, sustainability and human rights, and act in the construction of mechanisms that would enable practical actions, such as care, training and research. From this, we tried to analyze the relationship between accessibility and sustainability in the context of guaranteeing human rights, as tools for building inclusive and sustainable public policies.

Keywords: Social Inclusion. People with disabilities. Accessibility. Citizenship. Sustainability.

\footnotetext{
* Mestrando em Educação pela Pontifícia Universidade Católica do Rio Grande do Sul (PUCRS). E-mail: <jorgeamaroborges@gmail.com>.
} 


\section{Introdução}

A Fundação de Articulação e Desenvolvimento de Políticas Públicas para Pessoas com Deficiência e Pessoas com Altas Habilidades no Rio Grande do Sul (FADERS) é o órgão responsável por coordenar e articular projetos e ações direcionadas a essa parcela da população na estrutura do Estado.

Segundo o Censo 2010 do Instituto Brasileiro de Geografia e Estatística (IBGE, 2010), aproximadamente 45 milhões de brasileiros declararam possuir alguma deficiência, o que significou um salto de 1,41\% em 1991 para $14,5 \%$ da população em 2000, chegando a 23,9\% em 2010. A principal razão para o grande aumento no número de pessoas com deficiência é a alteração dos instrumentos de coleta de informações, incluindo o modelo social. Há também um acréscimo da população com deficiência no Brasil devido ao aumento da expectativa de vida da população e da violência urbana (assaltos, violência no trânsito, entre outros motivos), que vem alterando paulatinamente o perfil dessa população, que era, anteriormente, o de deficiências geradas por doenças.

O Brasil é um dos poucos países que possui legislação específica para esse público. Hoje, no mundo, menos de 50 países possuem tais instrumentos. Apesar disso, as condições básicas de saúde, educação, transporte, trabalho e cidadania precisam avançar em muitos aspectos. O direito de ir e de vir é garantido a todas as pessoas desde a Declaração Universal dos Direitos Humanos e encontra-se consagrado em nossa Constituição Federal. Por outro lado, o direito de comunicar-se é condição essencial para qualquer ser humano que vive em sociedade e, portanto, básico para o exercício de sua cidadania e garantia de sua dignidade.
Com base em tais princípios, todas as medidas necessárias para a eliminação de barreiras arquitetônicas e de comunicação que impedem a inclusão social das pessoas com deficiência deveriam ser adotadas pelo Poder Público como forma de promover o bem de todos, um dos objetivos fundamentais da República Federativa do Brasil (art. $3^{\circ}$, § IV, CF/88) (BRASIL, 1988). Além disso, consta da nossa Constituição de 1988 que a criação de programas e atendimento especializado para as pessoas com deficiência física, sensorial ou mental, mediante o treinamento para o trabalho e a convivência, é obrigação do Estado, assim como a facilitação do acesso aos bens e serviços coletivos, com a eliminação de preconceitos e obstáculos arquitetônicos (art. 227, § $1^{\circ}$, inciso III). Consta ainda, no mesmo artigo, que a lei disporá sobre normas de construção dos logradouros e dos edifícios de uso público e de fabricação de veículos de transporte coletivo, a fim de garantir acesso adequado às pessoas portadoras de deficiência $\left(\S 2^{\circ}\right)$ (BRASIL, 1988).

Nesse sentido, foram editadas as Leis n. ${ }^{\circ}$ 10.048/00 (BRASIL, 2004) e n. ${ }^{\circ}$ 10.098/00 (BRASIL, 2004), regulamentadas pelo Decreto n. ${ }^{\circ}$ 5.296, de 2 de dezembro de 2004. A primeira dá prioridade de atendimento às pessoas com dificuldade de locomoção. Já a Lei n. ${ }^{\circ}$ 10.098/00 estabelece normas gerais e critérios básicos para a promoção de acessibilidade das pessoas portadoras de deficiência ou com mobilidade reduzida, mediante a supressão de barreiras e de obstáculos nas vias e espaços públicos, no mobiliário urbano, na construção e reforma dos edifícios (inclusive os privados destinados a uso coletivo) e nos meios de transporte e comunicação. O cumprimento de tais direitos deve ser cobrado e eventuais denúncias devem ser encaminhadas aos Ministérios Públicos Estaduais, caso refiram-se a espaços 
e prédios públicos de responsabilidade do Estado ou do Município e espaços privados, e ao Ministério Público Federal, quando os espaços e prédios públicos são de responsabilidade da Administração Pública Federal. Já há algum tempo as questões relativas ao desenvolvimento sustentado e à educação ambiental vêm fundindo-se na intenção de gerar uma nova perspectiva nas relações HOMEM-AMBIENTE. E essa intenção é transportada para a realidade de um grupo na sociedade que muitas vezes encontra-se marginalizado e impossibilitado de exercer sua cidadania.

Considerando a importância da temática ambiental e a visão integrada do mundo, no tempo e no espaço, as políticas públicas ambientais devem oferecer meios efetivos para que cada indivíduo compreenda os fenômenos naturais, as ações humanas e suas consequências para consigo, para sua própria espécie, para os outros seres vivos e o ambiente. É fundamental a adoção de posturas pessoais e comportamentos sociais construtivos, colaborando para a construção de uma sociedade socialmente justa, em um ambiente saudável. Dessa forma, o Laboratório de Educação Ambiental - LEAI, proposto pela FADERS, é um espaço de referência na produção de práticas ambientais inclusivas. As ações contemplarão a diversidade humana de forma a garantir a participação de TODOS e TODAS em suas atividades. É um novo conceito que se estabelece no contexto ambiental, que busca visualizar no sujeito suas possibilidades a partir de uma ampla valorização da VIDA HUMANA.

Além de possuir espaços sustentáveis, como horta ecológica, compostagem, reciclagem, o LEAI se propõe a sensibilizar diferentes atores sociais para a inclusão e cidadania e para uma discussão conceitual, sociológica, antropológica e política sobre a articulação dos conceitos da acessibilidade e da sustentabilidade. É o primeiro espaço com essas características nas esferas do governo do Estado. Tem como objetivo central criar um espaço que propicie o desenvolvimento da formação continuada, da capacitação e da pesquisa em Educação Ambiental num âmbito global, interdisciplinar e transversal, tendo como princípios fundamentais a inclusão social e a sustentabilidade ambiental. As conquistas ao longo do último ano reforçam nossa certeza de estar trilhando um caminho correto e coerente.

\section{Material e método}

A partir da concepção do paradigma da inclusão ${ }^{1}$, a FADERS, na sua função de articuladora da política pública para pessoas com deficiência e com altas habilidades no Rio Grande do Sul, provocou o debate de metodologias que promovem uma educação ambiental efetivamente para todos. Diante disso, alguns mecanismos foram estabelecidos. A primeira ação partiu da necessidade de estabelecer um diálogo intersetorial nos espaços e projetos de governo. Iniciamos, no ano de 2002, com a instituição da Oficina de Educação Ambiental no Centro Abrigado Zona Norte, unidade da FADERS voltada ao atendimento de pessoas com deficiência intelectual, sensorial e deficiências múltiplas.

No ano de 2004, implantamos nesse espaço o projeto Sala Verde, em parceria com o Ministério do Meio Ambiente. A partir dessa experiência, estabelecemos parceria com a Secretaria Estadual do Meio

\footnotetext{
${ }^{1}$ A inclusão é um conceito que aprimora-se e conduz a disputas no campo educacional, pois propõe o desafio de inserir alunos com déficits de toda ordem, permanentes ou temporários, mais graves ou menos severos no ensino regular, na perspectiva de garantir o direito de todos à educação - e assim diz a Constituição Federal de 1988.
} 
Ambiente e prefeituras municipais de Bento Gonçalves, Charqueadas e Alvorada.

Em 2009, realizamos mapeamento das condições de acesso às pessoas com deficiência nas Unidades de Conservação do RS, no Jardim Botânico, no Museu de Ciências Naturais e no Jardim Zoológico.

Objetivamente, nossos trabalhos buscaram primeiro refletir sobre a necessidade de diálogo entre a Política Nacional de Educação Ambiental e a Política Nacional de Educação Especial na Perspectiva da Educação Inclusiva e atuar na construção de mecanismos que possibilitassem ações práticas, tendo como eixos centrais atendimento, capacitação e pesquisa.

\section{Resultados e discussão}

A Política Nacional de Educação Especial na Perspectiva da Educação Inclusiva, Documento elaborado pelo Grupo de Trabalho nomeado pela Portaria ${ }^{0} 555 / 2007$, prorrogada pela Portaria no 948/2007, entregue ao Ministro da Educação em 07 de janeiro de 2008, tem por objetivos "assegurar a inclusão escolar de alunos com deficiência, transtornos globais do desenvolvimento e altas habilidades/superdotação, orientando os sistemas de ensino para garantir: acesso ao ensino regular, com participação, aprendizagem e continuidade nos níveis mais elevados do ensino; transversalidade da modalidade de educação especial desde a educação infantil até a educação superior; oferta do atendimento educacional especializado; formação de professores para o atendimento educacional especializado e de demais profissionais da educação para a inclusão; participação da família e da comunidade; acessibilidade arquitetônica, nos transportes, nos mobiliários, nas comunicações e informação; e articulação intersetorial na implementação das políticas públicas” (BRASIL, 2008).

A Política Nacional de Educação Ambiental, Lei no 9.79/1999, em seu Art. $1^{\circ}$, destaca que Entendem-se por educação ambiental os processos por meio dos quais o indivíduo e a coletividade constroem valores sociais, conhecimentos, habilidades, atitudes e competências voltadas para a conservação do meio ambiente, bem de uso comum do povo, essencial à sadia qualidade de vida e sua sustentabilidade (BRASIL, 1999).

No VI Fórum Ibero-americano de Educação Ambiental, realizado em Joinvile, Santa Catarina, em 2006, houve, pela primeira vez, um debate temático sobre educação ambiental e educação especial. Nos anais do Fórum, o relatório final do Grupo de Trabalho trouxe como deliberação e proposta de encaminhamentos futuros Inserir o tema Educação Especial, envolvendo as pessoas com deficiência nas políticas públicas e programas de Educação Ambiental”(VIBEIRO, 2006).

O Fórum Brasileiro de Educação Ambiental, ocorrido em julho de 2010 na cidade do Rio de Janeiro, no mesmo Estado, trouxe um novo debate. Uma de suas jornadas temáticas tratou sobre "Educação Ambiental e Diálogos com a Diversidade”. No documento final do fórum, conhecido como a "Carta da Praia Vermelha”, destacou-se

A promoção do diálogo entre a Educação Ambiental e a diversidade, garantindo espaços de participação e decisão efetivas às pessoas com deficiência, comunidades tradicionais, indígenas, quilombolas, pequenos agricultores e outros atores em condições sociais vulneráveis. (FORUM REBEA, 2010)

Foi com base nesses princípios que a FADERS implementou, em 2009, o já citado Laboratório de Educação 
Ambiental Inclusiva - LEAI (Figura 01), com a função de estabelecer ações práticas de educação ambiental para todas as pessoas, independentemente de suas condições físicas, intelectuais ou sensoriais. A parceria com a Secretaria Estadual do Meio Ambiente (SEMA), através de Protocolo de Intenções (Figura 02); a reestruturação da Sala Verde, em parceria com o Ministério do Meio Ambiente (MMA); e o estabelecimento de convênio com o Centro Universitário Metodista, onde estagiários de ciências biológicas foram elementos que criaram condições para efetivação de uma política de educação ambiental inclusiva, foram medidas tomadas pela FADERS com vistas ao cumprimento dessa função atribuída ao LEAI.

Uma das primeiras ações do LEAI foi o mapeamento das condições de acessibilidade das unidades de conservação estaduais do Rio Grande do Sul. Dos 17 questionários aplicados, 11 foram respondidos, perfazendo um percentual de $65 \%$. A educação ambiental é trabalhada através de equipe própria em 8\% das unidades de conservação, sendo que em $64 \%$ delas há material gráfico específico. Em 27\% das UC, existem programas específicos de educação ambiental. Nas ações desenvolvidas destacam-se trilhas (21\%), cursos (7\%) e palestras (43\%); outras atividades, como reuniões comunitárias, exposições em eventos, fiscalização, vistorias, treinamento de educadores ambientais, projetos com escolas, coletivos educadores e sala verde itinerante, correspondem a 29\%. Quanto ao atendimento de pessoas com deficiência e pessoas com altas habilidades, não há registro na maioria das unidades, sendo que apenas $8 \%$ das UC disseram que realizam esse tipo de atendimento.

A acessibilidade universal aparece em apenas três UC, destacando-se acesso físico (29\%), rampas e corrimãos (29\%) e banheiro adaptado (42\%). Material em braile, intérprete de libras, trilhas adaptadas e vídeos legendados não aparecem em nenhuma resposta. Há poucos servidores qualificados na área de atendimento a pessoas com deficiência e com altas habilidades. O mesmo mapeamento se estendeu ao Museu de Ciências Naturais e Jardim Botânico, ambos em Porto Alegre (RS), e ao Jardim Zoológico, em Sapucaia do Sul (RS). Os três espaços se caracterizaram pela ausência de acessibilidade, profissionais sem qualificação específica nas áreas das deficiências e inexistência de materiais pedagógicos adequados às diferentes necessidades educativas especiais. A partir de todas essas reflexões, a FADERS incorpora em sua estrutura a temática ambiental e amplia sua capacidade de articulação de políticas inclusivas. E o diálogo e a participação dos protagonistas no processo têm possibilitado conquistas de extrema relevância social.

Em 2011, há necessidade de destacar algumas questões de grande impacto dessa ação, tanto internamente, como externamente. $\mathrm{Na}$ última reunião do Conselho Nacional dos Direitos da Pessoa com Deficiência (CONADE), uma das pautas foi relativa à participação do segmento no processo Rio+20² (Figura 03), que irá debater os vinte anos da ECO-92, assegurando-se, assim, que a acessibilidade

\footnotetext{
${ }^{2}$ A Conferência das Nações Unidas sobre Desenvolvimento Sustentável, a Rio+20, será realizada de 13 a 22 de junho de 2012, na cidade do Rio de Janeiro. A Rio+20 é assim conhecida porque marca os vinte anos de realização da Conferência das Nações Unidas sobre Meio Ambiente e Desenvolvimento (Rio-92) e deverá contribuir para definir a agenda do desenvolvimento sustentável para as próximas décadas. A proposta brasileira de sediar a Rio+20 foi aprovada pela Assembleia-Geral das Nações Unidas, em sua $64^{\text {a }}$ Sessão, em 2009. O objetivo da Conferência é a renovação do compromisso político com o desenvolvimento sustentável, por meio da avaliação do progresso e das lacunas na implementação das decisões adotadas pelas principais cúpulas sobre o assunto e do tratamento de temas novos e emergentes. Disponível em: http:// www.rio20.gov.br/sobre_a_rio_mais_20. Acesso em Acesso em: 10 nov. 2011.
} 
será um dos aspectos a serem garantidos a todas as pessoas na Conferência. Da mesma forma, o anúncio do Ministério da Educação de que o Programa Escolas Sustentáveis terá como princípios a acessibilidade, diversidade e direitos humanos é um passo importante na implementação de ações que articulem esses conceitos de forma institucional. Também foi construído, de forma coletiva, o Projeto Carbono Zero ${ }^{3}$, que buscou viabilizar que as entidades voltadas a atendimento das pessoas com deficiência possam refletir sobre responsabilidade ambiental. É importante registrar que conseguimos adesão de sete municípios a essa proposta.

Ao longo dos últimos anos, as reflexões e ações desenvolvidas pela FADERS têm pautado participação em eventos regionais e internacionais ${ }^{4}$ nos quais a educação ambiental e a inclusão procuram estabelecer conexões que reforçam o papel do LEAI como ferramenta nesses processos. As grandes ideias e propostas não nascem prontas, pois, como destaca MAIA (2000, p. 10), “a educação, sendo um processo que envolve o homem e a sociedade, muda no tempo e no

\footnotetext{
${ }^{3}$ O Projeto Carbono Zero busca construir uma cultura de sustentabilidade em todos os eventos voltados a pessoas com deficiência. Como forma de compensar o uso de recursos ambientais nesses eventos, são plantadas árvores após os mesmos. O foco central desse processo é valorizar o ato educativo através da sensibilização ambiental.

${ }^{4} \mathrm{O}$ trabalho desenvolvido na FADERS foi apresentado nos seguintes eventos: I Congresso Interamericano de Saúde Ambiental (2004); XXI Congresso Nacional das APAES e II Fórum de Auto defensores (2003); V Encontro de Biólogos da Região Sul (2002); I Congresso Internacional Transdisciplinar Ambiente e Direito (2004); I Congresso Brasileiro de Agroecologia/ / IV Seminário Internacional Sobre Agroecologia/ V Seminário Estadual Sobre Agroecologia (2003); Rio + 10 Aqui: a educação ambiental para a sustentabilidade (2002), XIII Encontro Paranaense de Educação Ambiental (2011); IV Colóquio de Pesquisadores de Educação Ambiental da Região Sul (2010); VI Fórum Brasileiro de Educação Ambiental (2009).
}

espaço. E, num tempo tão mutável como o de hoje, a educação encontra desafios e deve apresentar propostas novas e criativas”, as quais podem ser construídas a muitas mãos e infinitas mentes. Nesse entrelaçamento de processos, no início, foram pequenas oficinas, hoje são diálogos que extrapolam os limites do Rio Grande do Sul e do Brasil, consolidando como fonte desse trabalho a crença de que é possível acreditar na potencialidade das pessoas. Basta que as oportunidades sejam universalizadas.

Conforme Praxedes (2004), a democracia é um processo de negociação dos conflitos de interesses e ideias. Só que, para esse processo acontecer, o respeito à diferença é fundamental. Uma escola verdadeiramente democrática é aquela que, através do diálogo e do respeito à diferença, ensina os alunos a viverem em uma sociedade que também é pluralista e heterogênea.

A política do reconhecimento e as várias concepções de multiculturalismo nos ensinam, enfim, que é necessário que seja admitida a diferença na relação com o outro. Isto quer dizer tolerar e conviver com aquele que não é como eu sou e não vive como eu vivo, e o seu modo de ser não pode significar que o outro deva ter menos oportunidades, menos atenção e recursos. A democracia é uma forma de viver em negociação permanente tendo como parâmetro a necessidade de convivência entre os diferentes, ou seja, a tolerância. Mas para valorizar a tolerância entre os diferentes temos que reconhecer também o que nos une. (PRAXEDES, 2004)

Para Acselrad e Leroy (2001), o conceito de sustentabilidade pode ser desenvolvido através de três matrizes discursivas, sendo uma delas "a qualidade de vida". O "modelo da cidadania” é outra de suas vertentes, na qual a palavra cidadania 
retorna ao seu espaço de origem - a cidade -, sobrepondo-se ao sentido até aqui dominante, referente ao Estado-Nação, matriz em que se aborda a vida quotidiana da população urbana e o conjunto das políticas públicas a ela relacionadas. Uma sociedade sustentável é aquela que exercita a democracia, a participação e os direitos humanos, na qual um dos pilares fundamentais é o acesso de todas as pessoas a todos os espaços, de forma inclusiva.

\section{Conclusões}

As lacunas existentes entre sustentabilidade, acessibilidade e direitos humanos demonstram a dificuldade de incorporação, de forma articulada, de temas transversais no contexto das políticas públicas.

O trabalho desenvolvido na FADERS, através do LEAI, demonstra que a tensão entre essas questões é um processo emergente na atualidade, porém carece de aprofundamento devido à necessidade de superação de diversas barreiras no ponto de vista da discussão conceitual, o que ainda impede a execução de muitas ações.

Na medida em que uma ação iniciada em uma oficina com duas dezenas de pessoas com deficiência extrapola os muros do LEAI e ganha o contexto das políticas de Estado, o papel de ações locais como estruturantes para grandes mudanças na sociedade é significativamente reforçado.

O diálogo entre as áreas de sustentabilidade e de acessibilidade precisa de uma aproximação conceitual e metodológica, em que sejam alinhados os princípios da Convenção sobre os Direitos das Pessoas com Deficiência, da ONU, ratificada no Brasil em 2008 com valor constitucional, e da Agenda 21. Precisa, também, de estudos e indicadores que apontem para a convergência entre as reflexões, que permitam uma interlocução concreta entre a Política Nacional de Educação Ambiental e a Política Nacional de Educação Especial na Perspectiva da Educação Inclusiva.

\section{Agradecimento}

Agradeço a todos os aprendizes do CAZON pela tessitura e engajamento em um sonho possível e tão necessário.

\section{Referências}

ACSELRAD, H.; LEROY, J. P. Novas premissas da sustentabilidade democrática. Revista Brasileira de Estudos Urbanos e Regionais, n.1, 1999.

BRASIL. Constituição da República Federativa do Brasil. Brasília: Imprensa Oficial, 1988.

. IBGE. Censo demográfico, 2010. Disponível em: <http://www.ibge.gov.br/ home/estatistica/populacao/censo2000/ default.shtm>. Acesso em: 15 de jan 2012.

BRASIL. Ministério da Educação. Política Nacional de Educação Especial na perspectiva da Educação Inclusiva. Brasília: MEC, 2008.

Política Nacional de Educação Ambiental. Lei no 9.79/1999.

Secretaria de Educação Especial. Decreto $\mathrm{n}^{0} \mathbf{5 . 2 9 6}$ de 2 de dezembro de 2004. Regulamenta as Leis nos 10.048 , de 8 de novembro de 2000, que dá prioridade de atendimento às pessoas que especifica, e 10.098, de 19 de dezembro de 2000, que estabelece normas gerais e critérios básicos para a promoção da 
acessibilidade das pessoas portadoras de deficiência ou com mobilidade reduzida, e dá outras providências. Disponível em: <http:// www.planalto.gov.br/ccivil_03/_ato20042006/2004/decreto/d5296.htm>.

- Secretaria Especial dos Direitos Humanos. Acessibilidade. Brasília: SEDH, 2005.

CARTA da Praia Vermelha. Fórum Rebea, 18 jun. 2010. Disponível em: <http:// forumearebea.org/wp-content/uploads/ CARTA-DA-PRAIA-VERMELHA1.pdf $>$. Acesso em: 15 jul 2011.

MAIA, N. A. Introdução à educação moderna. Rio de Janeiro: UFRJ/CFCH, 2000. (memo).

PRAXEDES, $W$. A diversidade humana na escola: reconhecimento, multiculturalismo e tolerância. Disponível em: <http://www. espacoacademico.com.br/042/42wlap.htm>. Acesso em: 10 nov. 2011.

FÓRUM IBERO-AMERICANO DE EDUCAÇÃO AMBIENTAL, 6. Joinvile, SC, 2006. 1 CD.

Enviado em: 18/11/2011

Aceito em: 27/10/2011 